\title{
DESAIN DAN SIMULASI TUNGKU BAKAR UNTUK PENGOLAHAN PASIR BESI MENJ ADI SPONGE IRON DENGAN TEKNOLOGI TUNNEL KILN \\ DESIGN AND SIMULATION OF FURNACE FOR FERRUGINOUS SAND TO BE SPONGE IRON PROCESS BY USING TUNNEL KILN TECHNOLOGY
}

\author{
Barman Tambunan, Cuk Supriyadi, J uliansyah \\ Pusat Teknologi Industri Manufaktur - BPPT, Kawasan Perkantoran PUSPIPTEK, Gedung \\ Teknologi II (254) Serpong Tangerang Selatan, Banten 15314, Telepon (021) 75874944 ext. 1211 \\ e-mail : barman.tambunan@bppt.go.id, cuk.supriyadi@bppt.go.id, juliansyah@bppt.go.id
}

\begin{abstract}
Pasir besi merupakan salah satu potensi sumber daya alam yang tersebar di wilayah Indonesia. Pasir besi umumnya berupa magnetite (Fe304) dan hematite (Fe2O3) dengan kandungan pengotor berupa silica, alumina, dan titanium oksida. Untuk menaikkan nilai pasir besi, penelitian ini mengajukan tahapan proses antara lain proses benefisiasi dan proses reduksi menggunakan tungku bakar dengan teknologi Tunnel Kiln. Untuk mendapatkan proses reduksi yang optimal, dilakukan proses desain dan simulasi tungku bakar baik secara struktur maupun aliran fluida panas (Computional Fluid Dynamics/CFD). Penelitian ini menggunakan sampel pasir besi yang berasal dari kawasan pantai selatan pulau J awa, yaitu J awa bagian timur (lumajang), J awa bagian tengah (J ogja) dan J awa bagian Barat (Cipatujah). Untuk mengetahui performa hasil desain dan simulasi, dilakukan proses reduksi dengan menggunakan tungku bakar sesuai dengan desain. Performa hasil proses reduksi menghasilkan produk akhir Sponge Iron dengan kadar $\mathrm{Fe} 51.72 \%$ menjadi $78.79 \%$ dengan derajat metalisasi $36.68 \%$ (sampel J ogja) dan dari $52.93 \%$ menjadi $57.90 \%$ dengan derajat metalisasi $24.43 \%$ (sampel Lumajang). Dari hasil tersebut membuktikan bahwa tungku bakar dengan teknologi Tunnel Kiln ini dapat meningkatkan nilai tambah Pasir besi.
\end{abstract}

Kata Kunci : Pasir besi, Desain, Simulasi, Tunnel Kiln, Sponge Iron

Ferruginous sand is one of the natural resources that are scattered across Indonesia. Ferruginous sand is generally in the form of magnetite ( $\mathrm{Fe} 3 \mathrm{O} 4$ ) and hematite (Fe203) with a high content of impurities such as silica, alumina, and titanium oxide.To increase the value of Ferruginous sand, this study shows the stages of the process include mechanical beneficiation process and reduction process by using Tunnel Kiln technology.To get optimal production, carried out the Process design and simulation of combustion furnaces both structural and fluid flow of heat (CFD). This study used a sample of iron sand originating from the southern beach area of the island of J ava, that is from east J ava (Lumajang),Central J ava (Yogyakarta) and the west J ava (Cipatujah).To determine the performance result of design and simulation, have been done the actual reduction process by using the combustion furnace according to the design. Performance results of reduction process to produce a finish Sponge Iron with increased $\mathrm{Fe}$ content of $51.72 \%$ to $78.79 \%$ with $36.68 \%$ metallization degree (J ogja samples) and from $52.93 \%$ to $57.90 \%$ with $24.43 \%$ metallization degree (sample Lumajang). This results has prove that the furnace by using theTunnel Kiln technology could increase the value of the ferruginous sand. 
Diterima (received) : 10 Maret 2016, Direvisi (reviewed) : 17 Maret 2016,

Disetujui (accepted) : 5 April 2016

\section{PENDAHULUAN}

Pasir besi merupakan sumberdaya alam yang sangat melimpah dan tersebar diseluruh tanah air. Pasir besi terbentuk jutaan tahun yang lalu dari endapan batuan pada daerah pantai oleh hasil reaksi vulkanologi. Upaya pemanfaatan pasir besi lokal menjadi bahan baku material substitusi impor dengan nilai ekonomis yang lebih tinggi merupakan suatu tantangan yang membutuhkan pengelolaan yang baik, sumber daya manusia yang kompeten untuk melaksanakannya serta rencana pemanfaatan yang mantap dan konsisten pelaksanaannya. Hal ini diperkuat dengan diterbitkan UU Minerba UndangUndang No. 4 tahun 2009 tentang Mineral dan Batu Bara yang dalam pelaksanaannya diikuti beberapa aturan tentangn pelarangan ekspor bahan mineral tambang dalam bentuk mentah kecuali untuk beberapa material tambang tertentu sehingga perlu dilakukan proses penambahan nilai tambah pada bahan mineral tambang tersebut baik dengan teknologi pemurnian bahan tambang setengah jadi yang dikenal dengan istilah smelter dan proses pemurnian yang menghasilkan produk-produk jadi sebagai bahan baku industri hilir.

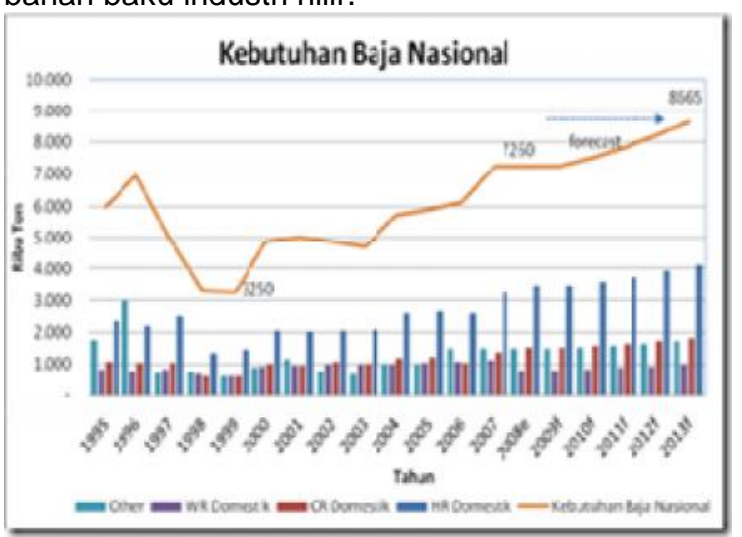

Gambar 1.

Kebutuhan Baja Nasional 1995 -2013

Berdasarkan data Kementerian Perindustrian diperkirakan kebutuhan akan baja kasar akan meningkat menjadi sebanyak 9,2 juta ton sementara industri dalam negeri hanya mampu memasok sebesar 5,4 juta, melalui produksi sponge iron sebesar 1,2 juta ton, dan baja kasar yang terdiri dari slab baja sebesar 1,2 juta ton dan billet baja sebesar 4,2 juta ton. (Data Statistik Industri, Kemenperin, 2013).
Selama ini pengolahan bahan tambang bijih/pasir besi masih berorientasi pada produksi skala besar dengan menggunakan peralatan high cost investment seperti Blast Furnace dan Rotary Kiln. Disamping kebutuhan investasi yang besar, untuk operasional peralatan tersebut membutuhkan pasokan energi yang cukup besar sehingga hanya terbatas hanyak untuk perusahaan yang memiliki tingkat modal yang cukup besar yang mampu untuk menjalankan industri pengolahan bahan tersebut. Hal inilah yang menjadi salah satu penyebab kurang berkembangnya industri pengolahan bahan tambang di Indonesia.

Teknologi Tunnel Kiln bukan teknologi baru di Indonesia karena sudah banyak industri yang menggunakannya, tapi aplikasi pada pengolahan bahan tambang belum dikenal luas di kalangan industri. Dalam hal kebutuhan energi, tunnel kiln dapat memanfaatkan potensi gas alam mengatasi permasalah-permasalahan di atas dengan mempertimbangkan kemampuan teknologi dalam negeri dengan didukung oleh sumber daya yang ada. yang masih sangat besar dan tersebar di seluruh wilayah Indonesia, namun karena kapasitas produksinya yang relative lebih kecil daripada peralatan yang lain sehingga kurang berkembang di industri komersial. Oleh karena itu teknologi ini perlu dikembangkan dalam skala usaha kecil menengah (UKM) namun terkoordinasi secara makro sehingga akan memiliki dampak yang signifikan terhadap industri besi-baja nasional

Pasir besi di alam bebas memiliki kandungan oksida besi yang berbeda sesuai dengan letak geografisnya, namun sebagian pasir besi mengandung senyawa magnetite ( $\mathrm{Fe} 3 \mathrm{O} 4)$, dan hematite ( $\mathrm{Fe} 2 \mathrm{O} 3$ ) serta unsur atau senyawa pengotor lainnya seperti Titanium, Silika dan Vanadium. Dalam mengidentifikasi material yang terkandung dalam pasir besi dilakukan berbagai metode karakterisasi material diantaranya dengan menggunakan X-Ray Fluoroscence (XRF) dan X-Ray Diffraction (XRD) serta diperkuat dengan Teknik Analisa Kimia Basah yang digunakan untuk mengidentifikasi senyawa ataupun unsur apa saja yang terkandung dalam pasir besi tersebut.

Sample pasir besi berasal dari kawasan pantai selatan pulau Jawa, yaitu Jawa bagian timur (lumajang), Jawa bagian tengah (Jogja) dan Jawa bagian Barat (Cipatujah) dengan rata-rata kadar $\mathrm{Fe}$ yang dimiliki sekitar 20-50 
Desain dan Simulasi Tungku Bakar untuk Pengolahan Pasir Besi Menjadi Sponge Iron dengan Teknologi Tunnel Kiln (Barman Tambunan, Cuk Supriyadi, Juliasyah)

\% dari massa senyawa pasir besi. Bahan yang digunakan sebagai reduktor (pengikat oksida) adalah karbon aktif yang berupa briket batubara dengan nilai kalor menengah (5000-6000 BTU) ditambah dengan bahan penguat struktur (binder) dari tepung tapioka (kanji) agar spesimen dapat dibuat menjadi briket

Secara mekanik kadar Fe dapat ditingkatkan melalui proses Benefisiasi menggunakan metode pencucian, penyaringan dan pemisahan antara material yang mengandung material magnetik dan non-magnetik menggunakan peralatan magnetik separator. Proses ini dapat meningkatkan kadar Fe sekitar 50-60\% dari massa senyawa pasir besi yang diidentifikasi.

Dalam proses peningkatan kadar Fe pada pasir besi menjadi produk sponge iron diperlukan dilakukan dengan proses reduksi baik proses reduksi langsung maupun proses reduksi tidak langsung. Dalam penelitian ini digunakan Tungku Bakar dengan sistem pembakaran periodik yang dengan parameter operasi yang digunakan dalam teknologi Tunnel Kiln terutama yang berkaitan dengan temperatur reduksi, waktu tahanan dan aliran panas yang terjadi pada proses reduksi tersebut. Untuk mendapatkan hasil optimal dari rancang bangun tunnel kiln, maka dalam skala lab kita simulasikan menggunakan software ANSYS untuk pemodelan struktur dengan beban mekanik dan simulasi aliran fluida (Computation Fluids Dynamics/CFD).

Untuk mengetahui hasil pembakaran yang berupa sponge iron, dilakukan proses identifikasi menggunakan metode karakterisasi X-Ray Diffraction (XRD). Dengan metode ini dapat diketahui unsur dan senyawa yang terkandung dalam sponge iron tersebut. Identifikasi juga dilengkapi dengan uji surface/permukaan sponge iron dengan metode Scanning Electron Microscopy Energy-dispersive X-ray spectroscopy (SEMEDX) sehingga didapatkan komposisi unsur yang ada pada permukaan benda uji sponge iron tersebut.

Dari data-data tersebut dapat diketahui derajat metalisasi dari produk sponge iron yang dihasilkan pada proses reduksi pasir pada tungku bakar dengan teknologi tunnel kiln. Derajat metalisasi merupakan gambaran nilai $\mathrm{Fe}$ murni yang memiliki sifat logam sehingga dapat digunakan sebagai bahan baku untuk industri logam berikutnya. Masing-masing sample memiliki derajat metalisasi yang berbeda tergantung keberhasilan proses reduksi yang dilakukan.D Parameter operasi yang optimal dapat diketahui dalam proses eksperimental yang disesuaikan dengan karakteristik bahan baku yang digunakan termasuk bahan-bahan pendukung seperti bahan pengikat (reduktor) dan bahan penguat (binder).

\section{BAHAN DAN METODE}

Metode yang digunakan dalam penelitian ditunjukkan pada gambar berikut:

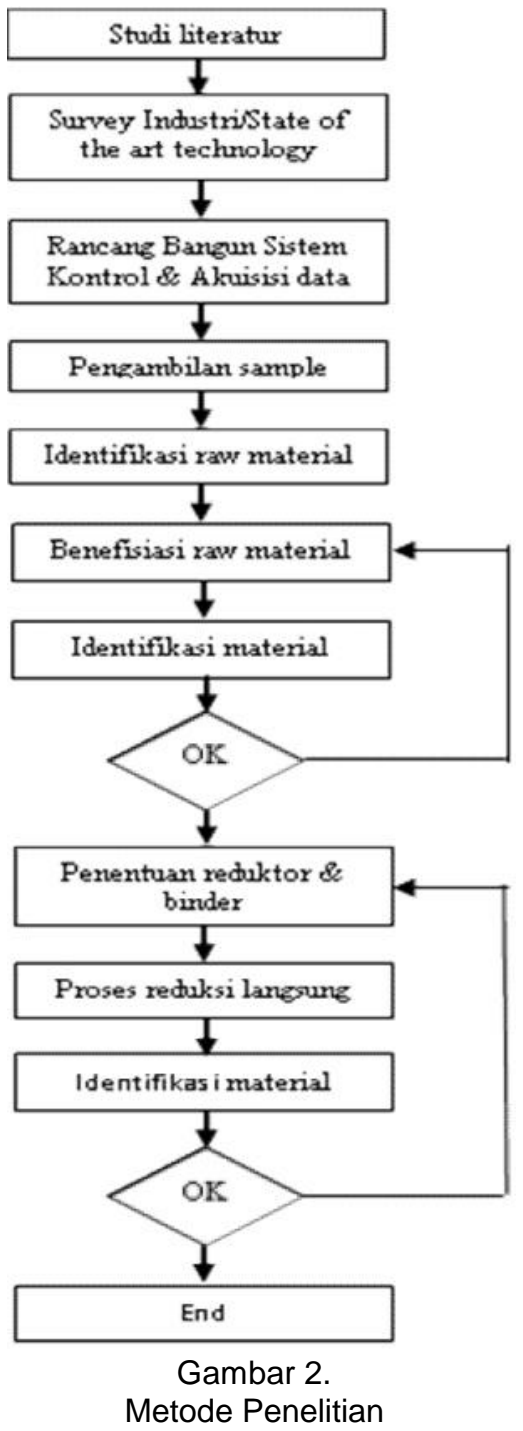

Metodologi ini merupakan strategi yang dilakukan dalam menangani pekerjaan berdasarkan pendekatan yang akan dilakukan. Secara garis besar metode penanganan pekerjaan ini meliputi metode study literature tentang proses pengolahan bijih/besi dengan proses reduksi langsung serta identifikasi karakteristik bahan baku. Selanjutnya dikembangkan suatu proses rancang bangun Tunnel Kiln termasuk instrumentasi akuisisi data sehingga dapat dilakukan simulasi pengolahan data sehingga 
didapatkan parameter operasi yang paling optimal.

Untuk mendapatkan data dan informasi yang cukup dan memenuhi dalam kegiatan inimetodologi yang akan digunakan antara lain adalah:

1. Studi Literatur.

Merupakan metode yang digunakan untuk mendapatkan berbagai data dan informasi mengenai proses reduksi pellet pasir besi menggunakan Tunnel kiln.

2. Survei Industri/State of the art (tunnel kiln)

Merupakan metode pengumpulan data secara langsung ke mitra industri atau instansi yang telah mengaplikasikan penggunaaan tunnel kiln sehingga didapatkan referensi teknis dari peralatan tersebut serta melakukan survei lokasi penambangan pasir besi dan pihak-pihak terkait untuk melengkapi kebutuhan data.

3. Rancang Bangun dan Simulasi

Rancang bangun Tunnel kiln dilakukan dengan cara membuat program dan instalasi komponen-komponen instrument seperti pada gambar 2. Rancang bangun tunnel kiln dilaksanakan pada program DIPA Industri Barang Modal 2015. Pada kegiatan program Insinas ini hanya melakukan rancang bangun akuisisi data dan sistem kendali.

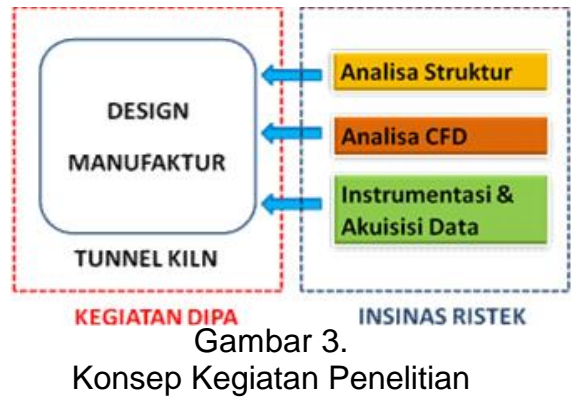

1. Pengambilan dan Identifikasi sampel material

Sample diambil di setiap wilayah-wilayah diprovinsi Pulau Jawa seperti Lumajang untuk Jawa Timur, Yogyakarta untuk DIY, dan Cipatujah untuk Provinsi Jawa Barat. Kemudian setiap raw material tersebut dilakukan proses identifikasi material untuk mengetahui komposisi unsur/senyawa yang terkandung didalamnya.

2. Proses Benefisiasi

Proses benefisiasi bertujuan untuk memurnikan kandungan yang diinginkan dengan mengurangi atau menghilangkan bahan pengotor yang ada. Proses benefisiasi dilakukan dengan proses pencucian, pengeringan, pemisahan dengan medan magnet (magnetic separator), pengayakan dan penghalusan

4. Penentuan Jenis serta Komposisi Bahan Pengikat dan Reduktor

Pellet pasir besi dicampur dengan zat aditif lainnya yaitu batu kapur sebagai fluks untuk menjaga kebasahan, bentonit sebagai binder (pengikat), kokas untuk menjaga kandungan karbon, dan air untuk menjaga kondisi kelembapan.

5. Proses Reduksi

Simulasi proses reduksi dilakukan dengan cara pemanasan cepat pada range temperature 800-1000 degC dengan periode waktu reduksi yang bervariasi 30-180 menit.

6. Uji Sampel dan Analisa

Metode karakterisasi X-Ray Diffraction (XRD) karena dengan metode ini dapat diketahui unsur dan senyawa yang terkandung dalam sponge iron tersebut. Identifikasi juga dilengkapi dengan uji surface/permukaan sponge iron dengan metode Scanning Electron Microscopy - Energy-dispersive X-ray spectroscopy (SEM-EDX) sehingga didapatkan komposisi unsur yang ada pada permukaan benda uji sponge iron tersebut.

- Keseimbangan Massa (Material Balance)

Merupakan metode analisis yang digunakan untuk menganalisis keseimbangan massa sebelum dan sesudah proses reduksi sehingga dapat diidentifikasi jumlah produk (persentase $\mathrm{Fe}$ ) dan limbah/emisi yang dihasilkan.

- Analisis Komposisi Kimia

Analisis komposisi kimia dilakukan dengan cara membandingkan hasil karakterisasi produk sponge iron yang dihasilkan dari hasil percobaan dengan standar sponge iron yang dibutuhkan industri dalam negeri.

- Analisis Parameter Operasi

Analisis parameter operasi ini digunakan untuk mendapatkan korelasi yang paling optimum antara temperature waktu pemanasan sehingga akan menghasilkan produk sponge iron dengan kandungan $\mathrm{Fe}$ yang paling tinggi. Data operasional tunnel kiln akan di akuisisi dengan software terintegrasi dengan komputer sehingga memudahkan dalam melakukan analisis dan reporting.

\section{HASIL DAN PEMBAHASAN}

Secara garis besar kegiatan penelitian ini dapat menghasilkan hal-hal sebagai berikut:

\section{Pengambilan Sampel}

Lokasi pengambilan sampel berada di wilayah selatan pulau Jawa dengan referensi potensi pasir besi baik dari buku maupun 
Desain dan Simulasi Tungku Bakar untuk Pengolahan Pasir Besi Menjadi Sponge Iron dengan Teknologi Tunnel Kiln (Barman Tambunan, Cuk Supriyadi, Juliasyah)

jurnal yang diterbitkan, maka dipilih 3 lokasi yang dianggap mewakili potensi sumber daya pasir besi tersebut dengan masing-masing lokasi diambil sampel kurang lebih $100-200$ $\mathrm{kg}$.

Pengambilan sampel dilakukan dengan manual dan berdasarkan informasi dari pihak terkait tentang lokasi yang paling berpotensi memiliki kandungan pasir besi yang paling baik, antara lain daerah stock pile, bekas galian tambang, pantai dan lain sebagainya.

- Jawa bagian timur, berlokasi di Pantai Pasirian, Kabupaten Lumajang - Jawa Timur.

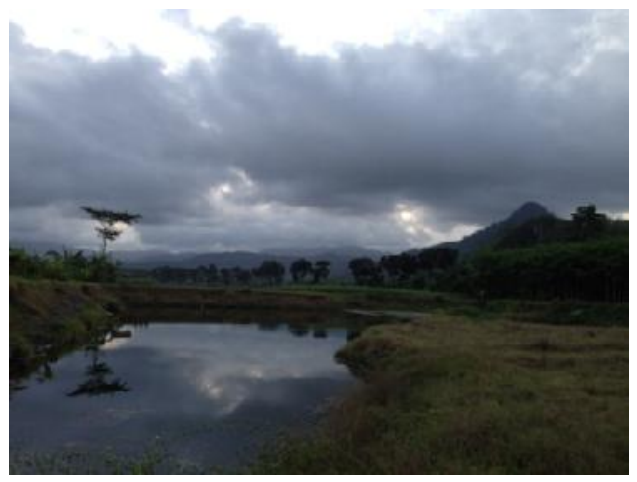

Gambar 4.

Lokasi di Lumajang

Jawa bagian tengah, berlokasi di Pantai Glagah, P Kwaru dan P Wates Kab. Wates Kulon Progo - DIY Jogjakarta.

- Jawa bagian barat, berlokasi di Pantai Cipatujah Kabupaten Tasikmalaya Jawa Barat.

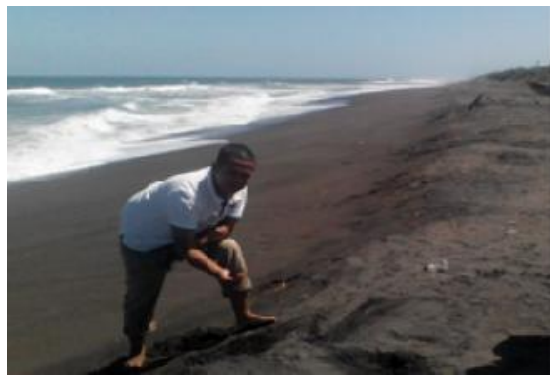

Gambar 5.

Lokasi di Pantai Kwaru - Jogja

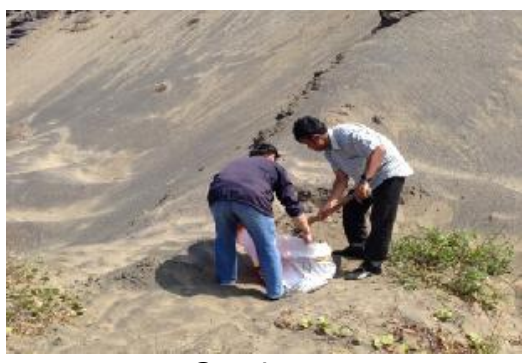

Gambar 6

Lokasi di Pantai Cipatujah - Tasik
2. Proses Identifikasi Material

Tabel 1

Hasil Identifikasi Raw Material dengan

Analisa Kimia Basah (B4T - Bandung

\begin{tabular}{|c|c|c|c|c|c|c|c|c|c|c|c|}
\hline \multirow{2}{*}{ Unsur Kimia } & \multicolumn{4}{|c|}{ Lumajans } & \multicolumn{2}{|c|}{ Tasik } & \multicolumn{5}{|c|}{ Yogyakarta } \\
\hline & R-1 & R-2 & R.-3 & W & $R-1$ & R.2 & $R \cdot 1$ & $R-2$ & R.-3 & R-4 & R.S \\
\hline slikgo & 49.72 & 55.8 & 50.05 & 28.32 & 21.93 & 56.77 & 47.16 & 64.08 & 75.33 & 63.01 & 42.5 \\
\hline Besj Oks da & 36.91 & 31.39 & 31.35 & 61.65 & 63.87 & 23.8 & 40.5 & 25.86 & 14.76 & 25.69 & 42.34 \\
\hline Aluminium & 814 & 731 & 12.41. & 2.73 & 1.02 & 6.68 & 4.05 & 3.55 & 4.89 & 4.7 & 5.33 \\
\hline kalsium & 052 & 044 & 0.55 & 036 & 0.46 & 2.61 & 1.74 & 2.19 & 2.63 & 3.05 & 2.18 \\
\hline Magnesium Cksida & 169 & 156 & 187 & 101 & 0.55 & 186 & 1.87 & 0.94 & 0.63 & 0.62 & 156 \\
\hline Manzen & 0.79 & 099 & 098 & 139 & 159 & 0.85 & 1.58 & 1.11 & 0.59 & 1.18 & 197 \\
\hline TTtan Oksidg & 2.14 & 241 & 2.27 & 4.45 & 10.46 & 4.92 & 2.97 & 1.99 & 0.99 & 158 & 3.96 \\
\hline \multirow[t]{2}{*}{ Lain-lain } & 008 & 009 & 051 & 0.1 & 0.11 & 25 & 0.12 & 0.27 & 0.17 & 0.16 & 0.15 \\
\hline & 99.99 & 99.99 & 99.99 & و9.99 & و9.99 & $\$ 9.99$ & 99.99 & 99.99 & 99.99 & 9999 & 99.99 \\
\hline
\end{tabular}

Catatan: $\mathrm{R}=$ Raw Material, $\mathrm{W}=$ Washing (benefisiasi).

Dari hasil uji kimia basah diketahui bahwa sample dengan kadar besi oksida tertinggi berasal dari Yogyakarta, sedangkan dari daerah Lumajang relatif memiliki kadar besi oksida lebih homogen.

3. Proses Benefiasi

Proses Benefisiasi dilaksanakan dengan menggunakan beberapa tahapan proses seperti berikut:

a. Proses Pencucian dan Proses Pengeringan

Pencucian dilakukan dengan menggunakan air dan dikeringkan secara alami dengan sinar matahari.

b. Proses Pemisahan (Magnetic Separator)

Dry magnetic separator digunakan untuk memisahkan partikel-partikel pasir besi yang non magnetic dari partikelpartikel besi yang bersifat magnetic. Dari hasil experimental yang dilakukan dengan peralatan dry magnetic separator jenis rotary diperoleh trend pola persentase pasir besi magnetic dari berbagai sumber lokasi seperti hasil Tabel 2:

Tabel 2.

Hasil Magnetic Sparator

\begin{tabular}{|c|c|c|c|c|}
\hline Area & Lokasi & Identitas. & $\begin{array}{c}\text { No. } \\
\text { Sample }\end{array}$ & $\begin{array}{c}\text { Benefisias } \\
\text { (MS) }\end{array}$ \\
\hline \multirow[t]{3}{*}{ Jawa Bag. Timur } & Lumajarg & Hasil Separator & A1 & $99 \%$ \\
\hline & & Raw Mat & A2 & $64 \%$ \\
\hline & & Ex-Gallan & $A 3$ & $38 \%$ \\
\hline \multirow[t]{4}{*}{ Jawa Bag. Tengah } & Jogja & P. Gagah & B1 & $75 \%$ \\
\hline & & P. Kwaru & B2 & $90 \%$ \\
\hline & & P. Samas & B3 & $82 \%$ \\
\hline & & P. Baru & B4 & $85 \%$ \\
\hline \multirow{2}{*}{ Jawa Bag. Barat } & Tasik & Stock Pile & C1 & $90 \%$ \\
\hline & Cipatujah & Sample 1 & C2 & $29 \%$ \\
\hline
\end{tabular}


c. Rancang Bangun Tunnel Kiln

Pemodelan 3 dimensi dari tunnel kiln skala lab dilakukan dengan menggunakan software Ansys. Hasil pemodelan dan simulasi diperlihatkan pada gambar di bawah.
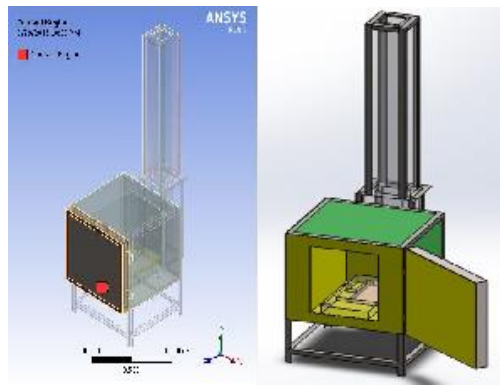

Gambar 7.

Model 3 Dimensi Tunnel Kiln Skala Lab

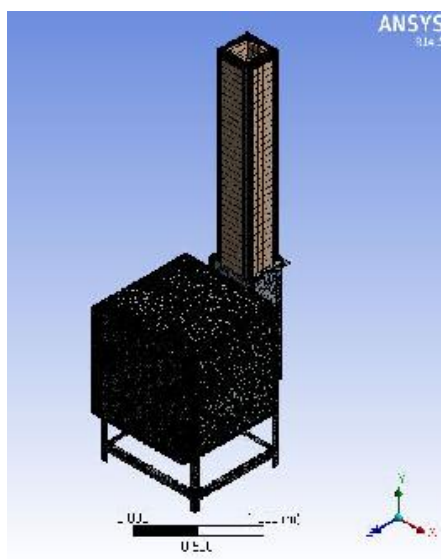

Gambar 8.

Meshing Tunnel Kiln Skala Lab

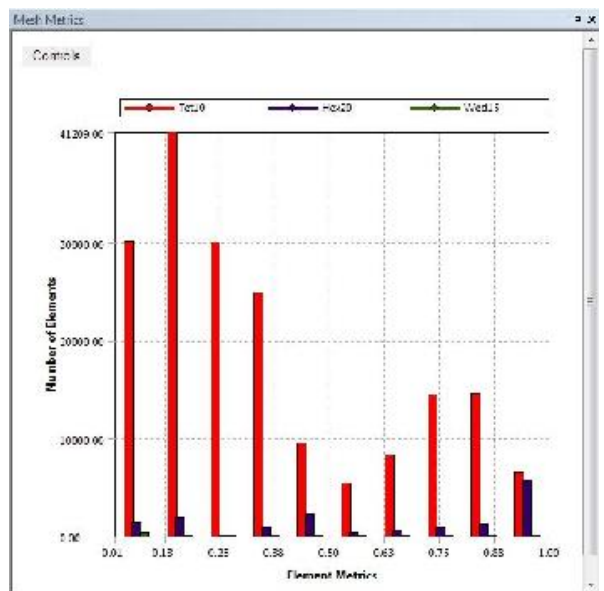

Gambar 9.

Matriks Kualitas Meshing Tunnel Kiln Skala Lab

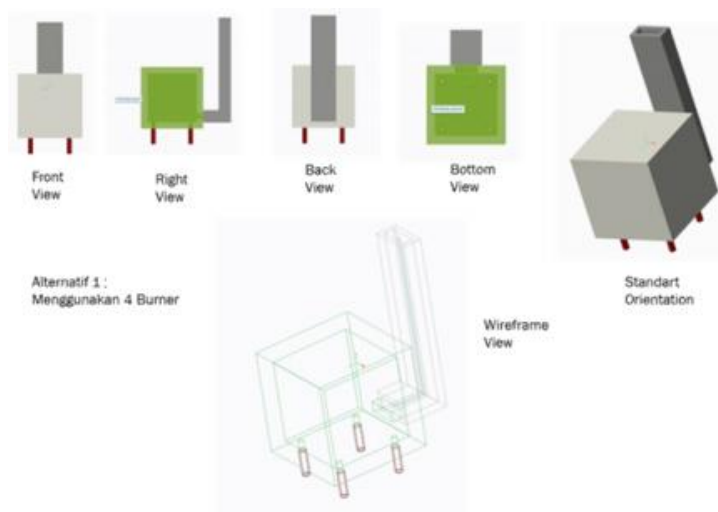

Desain Alternatif 1 (4 burner)
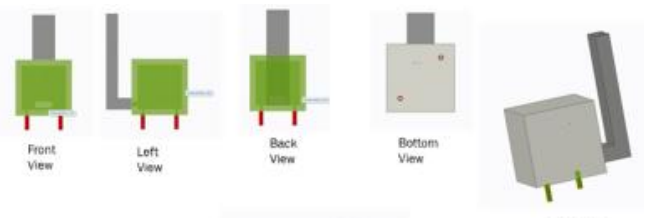

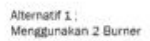
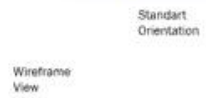

Desain Alternatif 2 (2 burner) Gambar 10.

Pemodelan Fluida

Simulasi Aliran panas menggunakan metode (Computation

Fluid

Dynamics)/CFD adalah penghitungan yang mengkhususkan pada fluida, mulai dari aliran fluida, heat transfer dan reaksi kimia yang terjadi pada fluida. Hasil perhitungan dan simulasi dengan menggunakan CFD diperlihatkan pada Gambar 10.

Pada saat melakukan simulasi untuk Fluida yang di pakai adalah udara panas dengan titik steady api di suhu $1200^{\circ} \mathrm{C}$, dengan kecepatan bakar $0.2 \mathrm{~m} / \mathrm{s}$ dan tekanan $0.5 \mathrm{~atm}$.ini adalah data asumsi standart untuk pembakaran menggunakan gas elpiji.

Hasil simulasi dengan menggunakan 4 Burner diperlihatkan pada Gambar 11. 

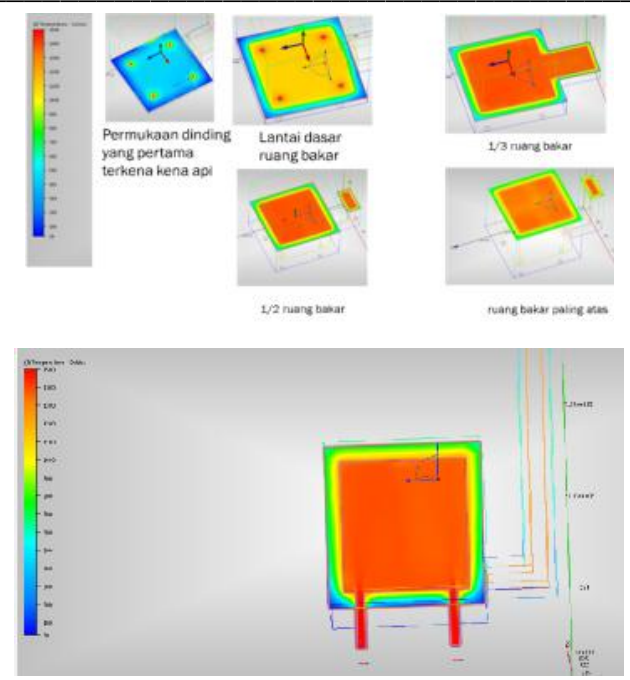

Gambar 11.

Hasil Simulasi dengan Menggunakan 4 Burner

Gambar 11 menunjukan bahwa arah radiasi dengan menggunakan 4 burner homogenitas sudah mendekati suhu leleh pasir besi bias $\left(<1200^{\circ} \mathrm{C}\right)$ dilihat pada gambar $1 / 3$ ruang bakar. Berdasarkan data ini pada saat pembakaran steady maka pasir besi mengalami pembakaran yang homogen.

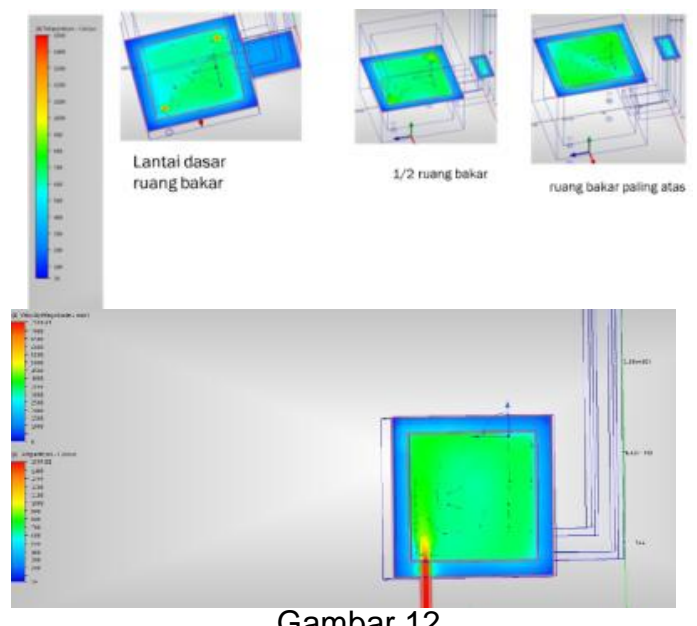

Gambar 12.

Hasil Simulasi dengan Menggunakan 2 Burner

Hasil simulasi dengan menggunakan 2 Burner diperlihatkan pada gambar 12, gambar tersebut menunjukan bahwa arah radiasi dengan menggunakan 2 burner belum mampu menghasilkan temperature yang mendekati titik leleh pasir besi.
Berdasarkan data diatas pada saat pembakaran steady maka pasir besi tidak bisa meleleh. Kuantitas burner sangat berpengaruh pada kebutuhan temperature ruang bakar yang diinginkan. Kuantitas burner menjadi salah satu faktor dalam penentuan temperature ruang bakar.

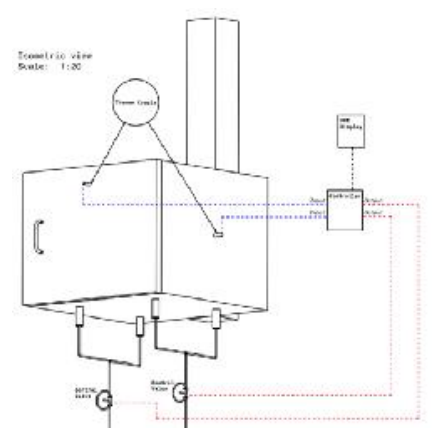

Gambar 13.

Sistem Akuisisi Data

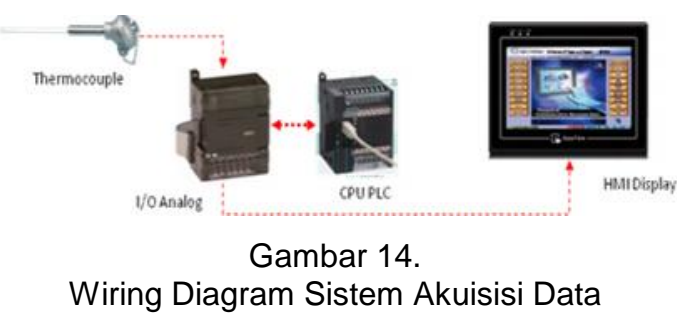

Tungku bakar dilengkapi dengan sistem akuisisi data untuk mencatat dan merekam temperatur didalam tungku bakar. Desain sistem akuisisi data diperlihatkan pada Gambar 13 dan wiring diagram sistem akuisisi data pada Gambar 14.

\section{d. Proses Pembakaran \\ - Uji Performa Tungku}

Spesimen di tambahkan reduktor yang digunakan yaitu briket batubara dengan variasi komposisi masing-masing $10 \%, 20 \%$, dan $30 \%$ sebagai berikut :

- Pasir Jogja + Reduktor Batubara $10 \%$

- Pasir Jogja + Reduktor Batubara $20 \%$

- Pasir Jogja + Reduktor Batubara 30\%

- Pasir Lumajang + Reduktor Batubara $10 \%$

- Pasir Lumajang + Reduktor Batubara $20 \%$

- Pasir Lumajang + Reduktor Batubara $30 \%$ 

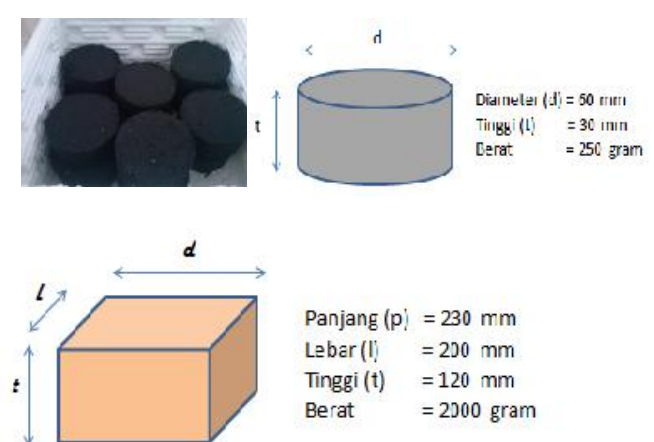

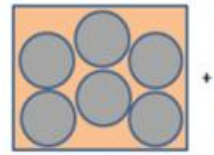

Lapis bawah
Lapis atas

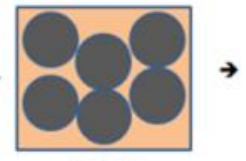

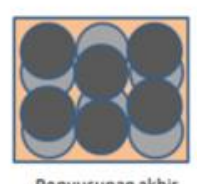

Penyusunanakhir
Gambar 15.

Penyusunan Briket Pasir Besi

Uji tungku dimulai dengan memasukkan sampel ke Tungku untuk kemudian dilakukan pembakaran. Tujuan uji tungku yaitu melihat kemampuan tungku untuk mencapai suhu sekitar $1200-1300^{\circ} \mathrm{C}$ seperti diperlihatkan pada Gambar 16 dan 17.

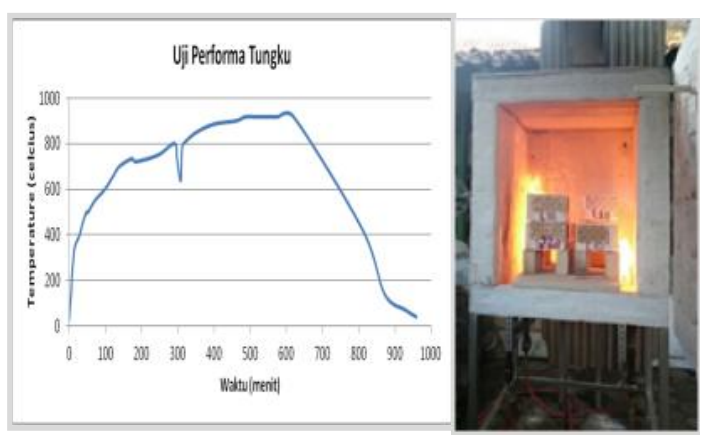

Gambar 16.

Diagram Fase Temperatur vs Waktu

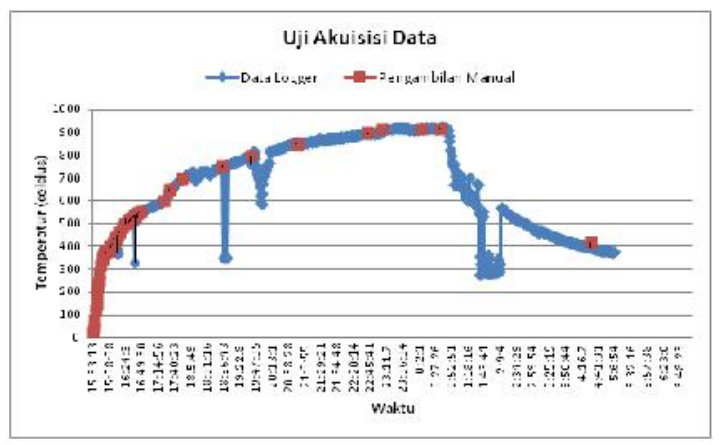

Gambar 17.

Diagram Fase Temperatur vs Waktu (Data logger)
Selama proses uji performa tungku dilakukan, trend peningkatan temperature hingga temperature $400^{\circ} \mathrm{C}$ cenderung linear dengan waktu sekitar 1 jam, dan untuk mencapai temperature di atas $800^{\circ} \mathrm{C}$ membutuhkan waktu sekitar 5 jam hingga akhirnya stagnan pada temperature $917^{\circ} \mathrm{C}$. Kondisi temperature stagnan kemungkinan disebabkan oleh dua hal yaitu beban tungku yang rendah dan design saluran panas buang yang belum optimal. Hal yang mendasari dari hipotesa ini adalah karena selama proses obong, terjadi fenomena fireback selama proses pembakaran. Fenomena fireback terjadi dikarenakan tekanan dalam tungku lebih tinggi daripada tekanan burner sehingga flame (nyala api) yaitu titik temperature tertinggi dari nyala api tidak masuk ke dalam ruangan tungku sehingga temperature dalam tungku tidak pernah lebih dari $917^{\circ} \mathrm{C}$.

\section{- $\quad$ Proses Reduksi Pasir Besi}

Dibuat briket untuk spesimen pembakaran dengan variasi lokasi pasir besi dan reduktor briket batubara(BB) dan Petroleum Coke(PC) dengan komposisi reduktor sebanyak $10 \%$ dari berat pasir besi

- Pasir Jogja + Reduktor BB 10\%

- Pasir Jogja + Reduktor PC 10\%

- Pasir Lumajang (Ben) + Reduktor BB $10 \%$

- Pasir Lumajang (Ben) + Reduktor PC $10 \%$

- Pasir Lumajang (S. pile) + Reduktor BB 10\%

- Pasir Lumajang (S. pile) + Reduktor PC $10 \%$

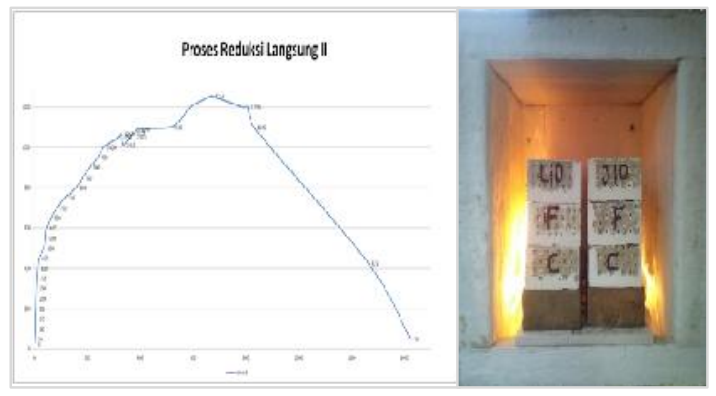

Gambar 18.

Diagram Fase Temperatur vs Waktu

Parameter proses dengan temperatur reduksi $1200^{\circ} \mathrm{C}$ dan waktu tahanan 3 jam dengan hasil seperti yang terlihat pada Gambar 18. 


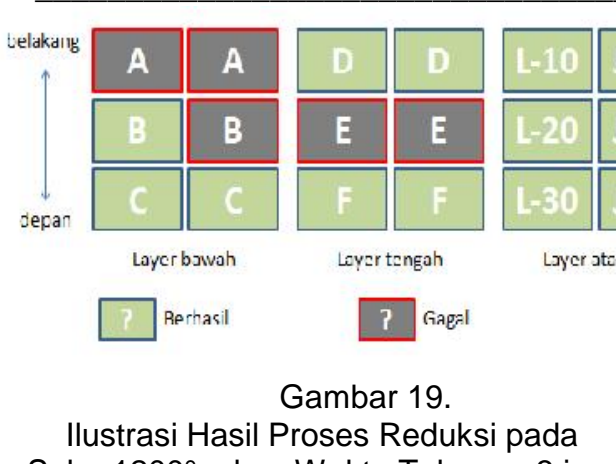

Suhu $1200^{\circ} \mathrm{C}$ dan Waktu Tahanan 3 jam

Dari hasil pembakaran menunjukkan bahwa temperatur dalam tungku tidak homogen, yang diindikasikan dengan munculnya fire back dan lidah api yang keluar dari cerobong tungku. Hal tersebut menyebabkan proses reduksi yang terjadi di masing-masing saggar tidak sama dengan yang lain seperti terlihat pada Gambar 19. Hal tersebut dapat dikarenakan supply bahan bakar dan udara pada masing-masing Burner tidak seimbang sehingga heat transfer tidak merata ke semua bagian tungku. Temperatur yang tercatat pada display Termokopel sampai pada titik tertinggi $1254{ }^{\circ} \mathrm{C}$ yang secara teoritis masih dibawah titik lebur dari pasir besi namun terjadi Over Heating sehingga muncul lelehan slag dan bahkan di dapatkan 2 saggar spesimennya terlebur habis sehingga tidak menghasilkan sponge iron.

\section{Hasil Uji Komposisi}

Dari hasil briket yang menjadi sponge iron diambil 2 sampel yang mewakili masing-masing lokasi dan menggunakan komposisi dan jumlah reduktor yang sama yaitu sampel Jogja dan Lumajang dengan reduktor Batubara $10 \%$ yang selanjutnya di uji dengan metode XRD dan SEM-EDX dengan hasil seperti pada Tabel 3 dan Gambar 20.

Tabel 3.

Hasil XRD sampel Jogja (\% massa)

\begin{tabular}{llllll}
\hline Komposisi & $\begin{array}{c}\text { Raw } \\
\text { Material }\end{array}$ & Washing & MS & Meshing & $\begin{array}{c}\text { Sponge } \\
\text { Iron }\end{array}$ \\
\hline Fe Total & 18.603 & 27.228 & 32.731 & 51.725 & 78.793 \\
Unsur lain & 81.397 & 72.772 & 67.269 & 48.275 & 21.207 \\
Total & 100 & 100 & 100 & 100 & 100 \\
\hline
\end{tabular}

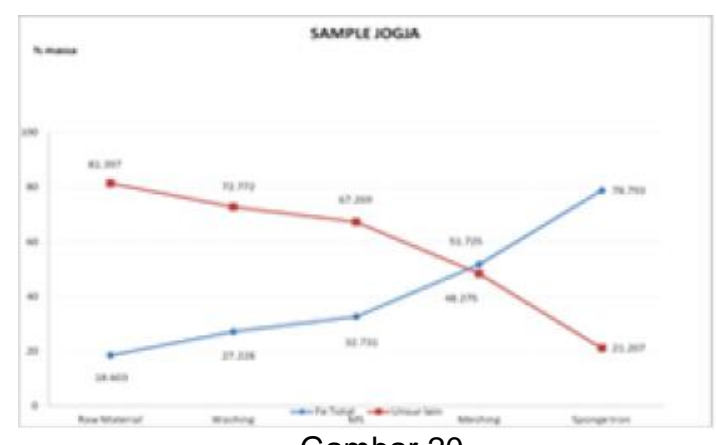

Gambar 20.

Peningkatan Kadar Fe di setiap tahapan proses sampel Jogja

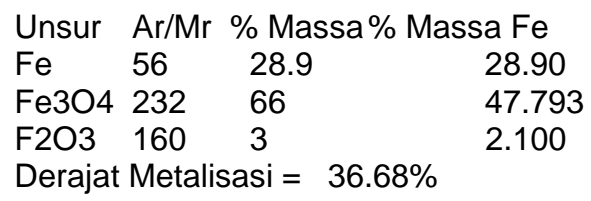

\section{SIMPULAN}

Benefisiasi merupakan salah satu parameter kunci keberhasilan pembuatan sponge iron menjadi bahan baku industri baja, semakin tinggi kandungan $\mathrm{Fe} 3 \mathrm{O} 4$ \& $\mathrm{Fe} 2 \mathrm{O} 3$ pada pasir besi maka kandungan $\mathrm{Fe}$ yang terbentuk pada sponge iron juga akan semakin tinggi

Beberapa parameter kunci lainnya yang menentukan keberhasilan proses reduksi adalah gas pereduksi ( $\mathrm{CO}$ dan $\mathrm{H} 2$ ) hasil dari proses pembakaran fuel serta lamanya waktu pembakaran

Derajat metalisasi dari sponge iron yang terbentuk adalah $36.68 \%$.

Diperlukan peralatan benefisiasi berupa variable magnetic separator yang kekuatan medan magnetiknya dikendalikan dengan pengaturan arus agar diperoleh pasir besi dengan kandungan oksida besi $>99 \%$

Diperlukan pemasangan motorized selenoid valve untuk pengaturan rasio fuel vs oksigen secara otomatis sehingga diharapkan reaksi yang terjadi di dalam tungku benar-benar merupakan reaksi

reduksi, serta peralatan monitoring gas pereduksi selama proses pembakaran untuk mengidentifikasi trend gas reduktor;

Perlu dilakukan pemodelan dan simulasi perpindahan panas pada sampel sponge iron, agar distribus perpindahan panas selama proses reduksi homogen. 


\section{UCAPAN TERIMA KASIH}

Penulis mengucapkan terima kasih kepada Kementerian Riset, Teknologi dan Pendidikan Tinggi atas bantuan biaya pada program Insentif SINAS Tahun 2015, juga ucapan terima kasih kepada Tim Insentif SINAS RT 2015 - 0376 sebagai pelaksana program dan pada semua pihak yang telah membantu.

\section{DAFTAR PUSTAKA}

1. Adil, Jamali., Pengolahan Pasir Besi Titan Menjadi Hot Metal dengan Tungku Induksi Listrik. Blog Sivitas LIPI ISSN 2086-5252 insentif, 2015.

2. Akhyar, Ibrahim, llyas Yusuf dan Azwar., Identifikasi Senyawa Logam dalam Pasir Besi di Propinsi Aceh, Majalah IImiah BISSOTEK, Vol. 7, No. 1 44-51, 2012.Firmansyah , Wahyu, Tesis: Telusuran Eksperimental Proses Reduksi Langsung Pellet Pasir Besi Menjadi Ingot Besi, Program Studi Magister IImu Bahan, Fakultas Matematika dan IImu Pengetahuan Alam, Universitas Indonesia, 2009.

3. Kopfle, T., Depelopment of Direct Reduction in the iron and Steel Industry. Direct Reduced Iron Teknology and Economics of Productions and Use. The Iron and Steel Society., Warrendale, Hal 3-8, 1999.
4. Ishlah, Teuku., Perekayasa Madya Pusat Sumber Daya Geologi, Potensi Bijih Besi Indonesia Dalam Kerangka Pengembangan Klaster Industri Baja, 2011.

5. Pramusanto, Sriyanti, Ariefandin, Prosiding SNaPP2010, Edisi Eksata, ISSN:2089-3582, Perbandingan Antara Penambahan Bentonit Dan Penambahan CMC Terhadap Hasil Proses Peletasi Pasir Besi, Jurusan Teknik Pertambangan UNISBA, 2010.

6. Pramusanto, Sriyanti, Ariefandin., Perbandingan antara Penambahan Bentonit dan Penambahan CMC terhadap Hasil Proses Peletasi Pasir Besi, Prosiding SNaPP2010 Edisi Eksakta ISSN: 2089-3582, 2012.

7. Suharto, Yayat Iman Supriyatna, Muhamad Amin, Prosiding Insinas 2012, 0805: Proses Reduksi Bijih Besi Lampung Menjadi Sponge Iron Menggunakan Rotary Kiln, UPT. Balai Pengolahan Mineral Lampung, LIPI, 2012.

8. Sun, S. A Study of Kinetics and Mechanism of Iron Ore Reduction in Ore/Coal. 1997.

9. Yayat, Muhammad Amin, dan Suharto., Study Penggunaan Reduktor pada Proses Reduksi Pelet Bijih Besi Lampung Menggunakan Rotary Kiln, Prosiding SNaPP2012: Sains, Teknologi, dan Kesehatan ISSN 2089-3582, 2012. 